\title{
SISTEM MONITORING JARINGAN PADA SERVER LINUX DENGAN MENGGUNAKAN SMS GATEWAY
}

\author{
Taufan Dwi Prayogo ${ }^{1}$, Kushartantya ${ }^{2}$, Helmie Arif Wibawa ${ }^{2}$ \\ Program Studi Teknik Informatika FMIPA UNDIP
}

\begin{abstract}
ABSTRAK
Administrator jaringan bertanggung jawab melakukan monitoring jaringan terhadap suatu jaringan komputer. Monitoring harusnya dilakukan secara terus menerus untuk menjaga kualitas jaringan, karena kesalahan pada jaringan tidak bisa dideteksi kapan terjadinya. Hal ini akan menyulitkan jika administrator berada jauh dari pusat pengawasan. Situasi ini bisa berakibat fatal jika terjadi kesalahan jaringan yang tidak diketahui karena administrator jaringan sedang tidak ada di tempat pengawasan. Dengan memanfaatkan teknologi SMS gateway yang menggunakan server berbasis Linux, administrator jaringan dapat mendapatkan informasi kondisi server secara cepat. Hasil yang didapatkan adalah sebuah sistem yang mampu membantu administrator jaringan dalam melakukan monitoring jaringan kapan saja dan dimana saja untuk menjaga jaringan akan tetap stabil walaupun administrator jaringan sedang tidak di pusat pengawasan.
\end{abstract}

Kata Kunci: Monitoring jaringan, SMS gateway, Server Linux.

\section{Pendahuluan}

Pesatnya kemajuan jaman menuntut semua orang untuk selalu update segala informasi dari berbagai sumber. Internet merupakan salah satu sumber informasi yang paling banyak digunakan masyarakat saat ini. Kemajuan itu pula yang membuat masyarakat sudah dapat mengakses ke internet dengan berbagai cara dan tempat. Didukung dengan banyaknya Internet Service Provider (ISP) yang menyediakan layanan internet secara cepat membuat makin mudah dan murah dalam menggunakan internet.

Sebuah jaringan lokal yang terhubung dengan internet membutuhkan server yang dapat berfungsi sebagai router maupun gateway, sehingga komputer client dalam jaringan tersebut dapat melakukan komunikasi secara online. Sebuah server dituntut untuk dapat memberikan layanan real time secara 24 jam. Terkadang karena banyaknya user yang mengakses melalui sebuah server menyebabkan kepadatan arus jalur data pada jam-jam tertentu yang menyebabkan gagal koneksi atau Request Time Out.

Dalam pengelolaan sebuah server dibutuhkan seseorang yang memiliki kemampuan serta tanggung jawab yang tinggi dalam menjamin server tersebut dapat melayani komputer client dengan baik yang biasa disebut administrator jaringan. Tetapi kadang kala administrator jaringan tidak dapat mengawasi koneksi server secara 24 jam penuh, oleh karena itu untuk memperingan pekerjaan administrator jaringan dibutuhkan sebuah sistem yang dapat menginformasikan status koneksi dari server secara real time.

Dibutuhkan teknologi alternatif untuk membantu administrator jaringan mendapatkan informasi mengenai status koneksi jaringannya secara cepat dan akurat. Teknologi yang mungkin dapat digunakan adalah teknologi SMS, SMS tidak hanya dapat digunakan untuk berkomunikasi secara cepat dan murah, namun dapat dimanfaatkan dalam banyak hal. Salah satunya sebagai jaringan alternatif penghantar pesan untuk menginformasikan status koneksi server kepada admininstrator jaringan jika jaringan komputer terputus atau lumpuh. Kelebihan lain dari penggunaan SMS adalah dapat dibuat aplikasi yang menghubungkan server dengan administrator jaringan melalui jaringan SMS gateway, dengan tarif normal [6].

Untuk membuat teknologi SMS yang dapat membantu administrator jaringan, perlu dibuat sistem SMS gateway. Fungsi SMS gateway sebagai teknologi pendukung SMS agar dapat digunakan sebagai alert system. Penggunaan SMS gateway sebagai sistem yang melakukan pengiriman SMS secara otomatis. Sehingga administator jaringan akan menerima SMS tentang keadaan jaringannya yang dikirim melalui SMS gateway.

Teknologi monitoring jaringan yang sebelumnya hanya mengandalkan administrator 
jaringan untuk memantau server jaringannya. Kekurangan dari teknologi monitoring terdahulu adalah tidak adanya sistem yang memberitahukan administrator jaringan tentang kondisi koneksi server dan sebagian besar server yang digunakan adalah server berbasis Linux. Sehingga admininstrator jaringan harus berada dalam lingkungan server agar terus dapat memantau server. Pada tulisan ini akan dibahas tentang penerapan SMS gateway untuk sistem monitoring jaringan pada server Linux yang dapat membantu tugas administrator jaringan dalam pengawasan koneksi server.

\section{Short Messaging Service}

SMS (Short Messaging Service) adalah suatu layanan untuk mengirimkan pesan pendek (160 karakter) dari satu telepon GSM ke yang lainnya [6]. Layanan ini juga dapat digunakan untuk mengirim pesan teks regular seperti halnya logo operator, nada dering, isi kontak telepon, dan konfigurasi telepon. Layanan SMS berisi beberapa service yang dapat dihubungkan melalui pesan SMS untuk beberapa nomor telepon tertentu, yang dapat menjawab isi yang diminta, apabila tersedia. Sedangkan SMS gateway adalah aplikasi yang menyediakan antarmuka antara pesan SMS dan protokol lainnya dan menghubungkan perangkat mobile (Ponsel, PDA phone dll) dengan SMS Center [6].

\section{Tahapan Life Cycle Approach}

Dalam pengembangan sistem berbasis jaringan, metode pengembangan sistem yang digunakan menurut [1], Life Cycle Approach (Pendekatan daur hidup)

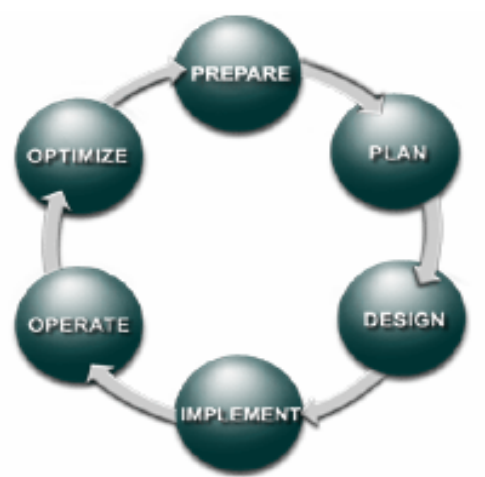

Gambar 1. Tahapan-tahapan life cycle

\section{a. Prepare}

Pada bagian ini dilakukan analisa untuk menjabarkan dan menempatkan strategi networking yang akan dibangun sesuai dengan infrastruktur IT (Information Technology) dan aspek finansial yang dikembangkan ke depan.

\section{b. Plan}

Pada bagian perencanaan, akan dipelajari tentang infrastruktur IT (hadware, software, topologi jaringan) yang telah berjalan dan digunakan. Tahapan ini meneruskan dari tahap prepare sebelumnya. Dengan perencanaan yang baik akan membantu untuk mengatur pekerjaan, resiko yang mungkin muncul, permasalahan yang ditemui, responsibility, tenggang waktu milestones, dan kebutuhan sumber daya yang dibutukan.

\section{c. Design}

Dalam tahap ini menjelaskan tentang bagaimana proses konfigurasi, koneksi percobaan, pengembangan ke depan, dan proses migrasi dari sistem lama ke sistem baru, demo sistem dan validasi.

\section{d. Implement}

Sebelum diimplementasikan akan dilakukan testing terlebih dahulu, hal ini dilakukan untuk meminimalisasi kesalahan yang mungkin muncul. Proses ditahapan ini adalah instalasi, konfigurasi, dan integrasi sistem. Bisa jadi salah satu bagian network telah berhasil dimigrasi dengan baik namun tidak berarti semua bagian akan lancar.

\section{e. Operate}

Tahap ini merupakan lanjutan dari tahap implementasi, dilakukan pengawasan dan pemantauan pada pengoperasiannya, beberapa kasus pada tahapan ini akan terlihat beberapa masalah misalnya tidak kompatibelnya hardware, masalah pada software dan aplikasi yang selama ini jalan tidak ada hambatan namun setelah implementasi menjadi terganggu.

\section{f. Optimize}

Masukan pada saat tahapan implementasi dan operate akan sangat mempengaruhi tahapan optimalisasi ini, masukan tadi bisa memberikan input untuk penanganan, redesign, rekonfigurasi dan perubahan yang 
perlu dilakukan tanpa merubah arah dari tujuan sistem tersebut.

\section{Perancangan}

Dalam pembangunan sistem monitoring jaringan dengan SMS gateway ini dibutuhkan tiga desain fungsional. yang pertama digunakan untuk menjelaskan urutan logis dalam konfigurasi sistem, kemudian kedua menggambarkan urutan logis uji koneksi ping dan yang ketiga adalah untuk uji koneksi database. Tabel berikut ini memaparkan desain fungsional konfigurasi

Tabel 3.1 Desain fungsional konfigurasi

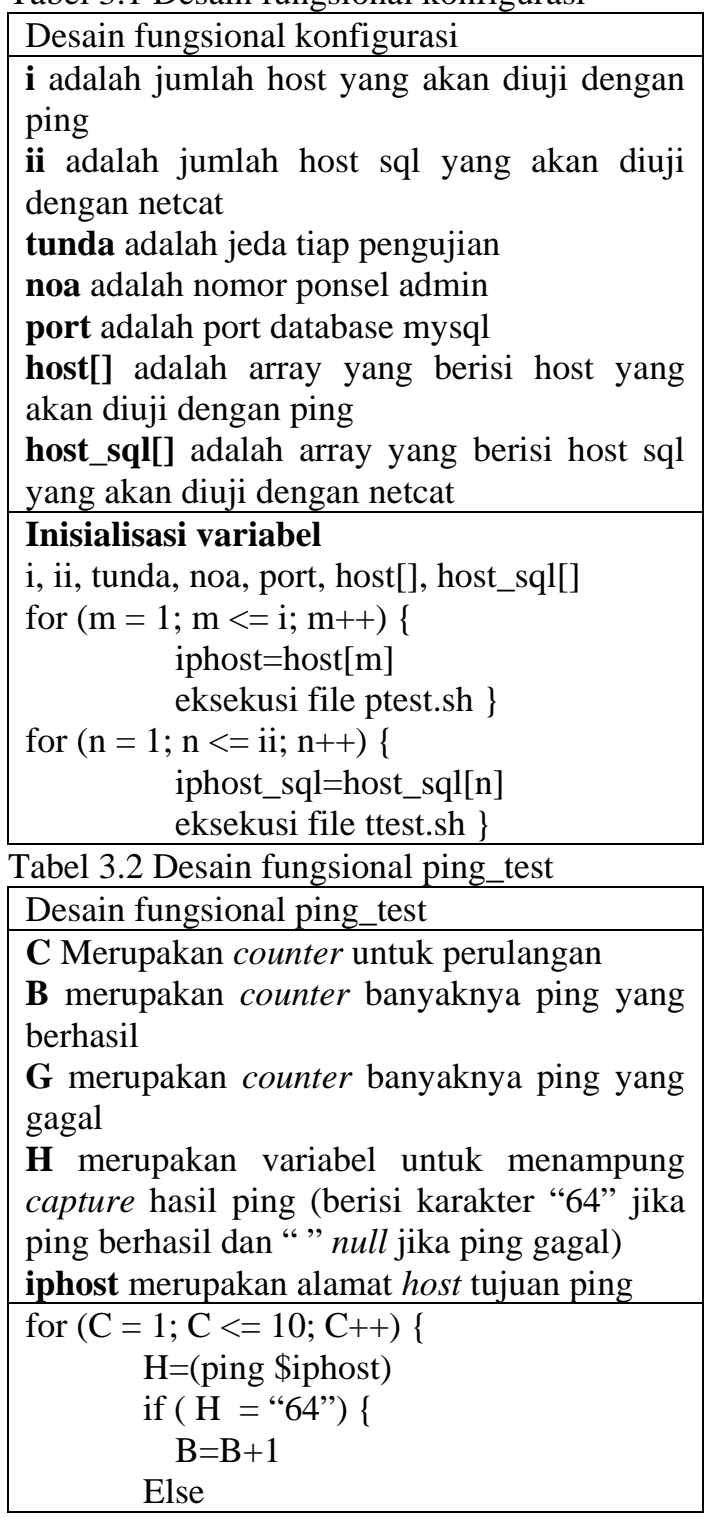

\begin{tabular}{|l|}
\multicolumn{1}{|c|}{\}$^{G=G+1}$} \\
if $\left(\mathrm{G}=\begin{array}{l}10) \\
\text { gammu send sms }\}\end{array}\right.$ \\
\hline
\end{tabular}

Tabel 3.3 Desain fungsional database_test

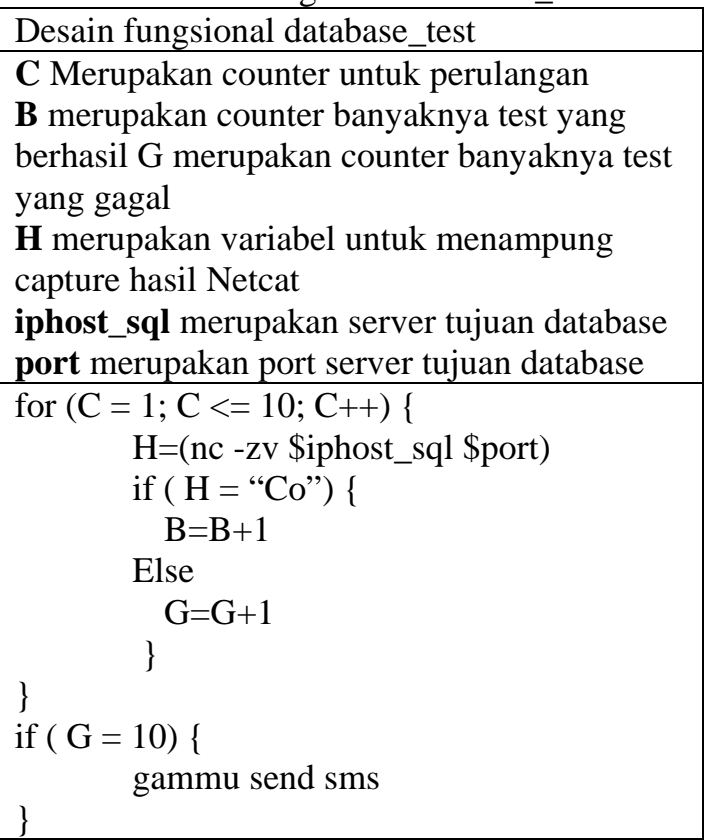

Perancangan dilakukan dengan membuat desain flowchart yang menggambarkan secara garis besar algoritma sistem, mulai dari sistem dijalankan hingga waktu terminasi. 

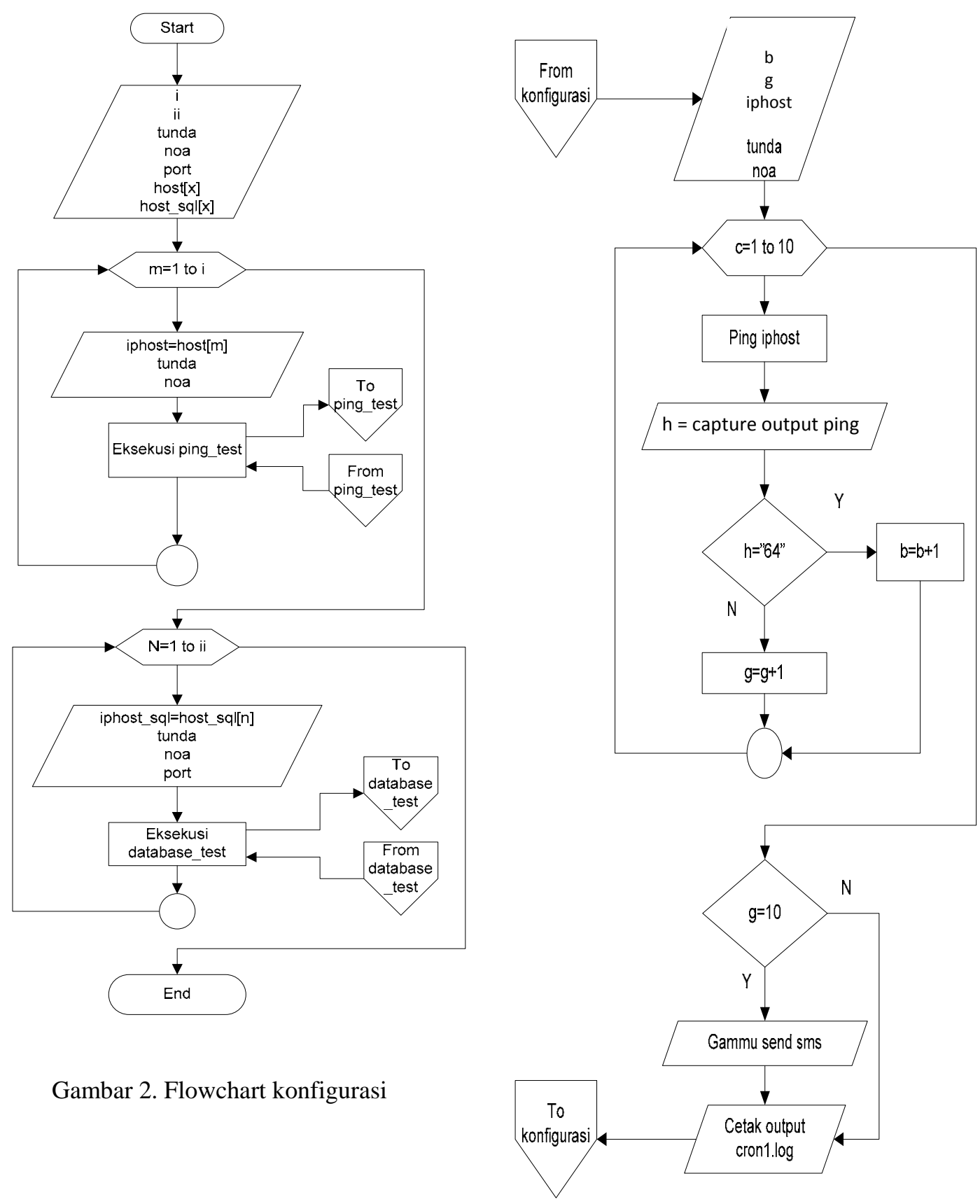

Gambar 3. Flowchart ping_test 


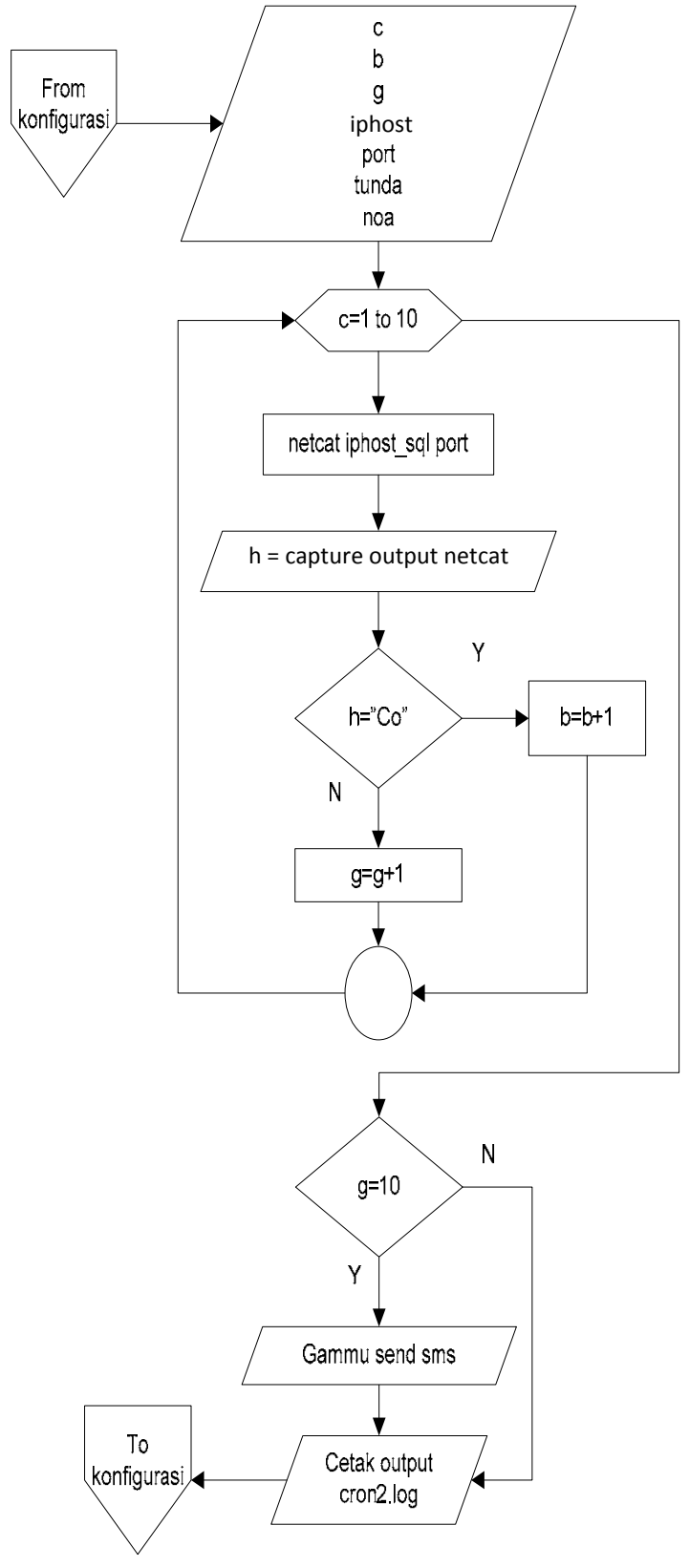

Gambar 4. Flowchart database_test

\section{Implementasi dan Pengujian Sistem 5.1. Implementasi}

Langkah -langkah dalam implementasi

a. Menyiapkan direktori script

Script yang dibuat nanti harus berada dalam direktori yang benar, agar sesuai manajemen direktori. Harus diletakkan pada direktori /usr/local/, direktori /usr bersifat shareable, yang berarti isi dari direktori /usr dapat digunakan oleh host lain.

b. Menyiapkan script uji koneksi dengan ping Perintah yang digunakan untuk membuat script uji koneksi dengan ping adalah

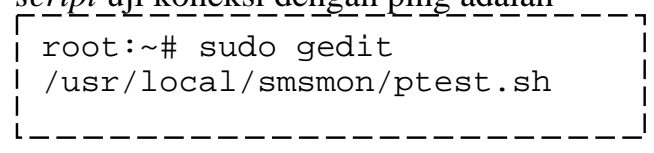

Dalam file ptest.sh, terdapat perintah untuk melakukan ping dan mengirim SMS sesuai dengan algoritma yang telah dibuat, implementasinya sebagaimana terlihat pada kode 1 berikut:

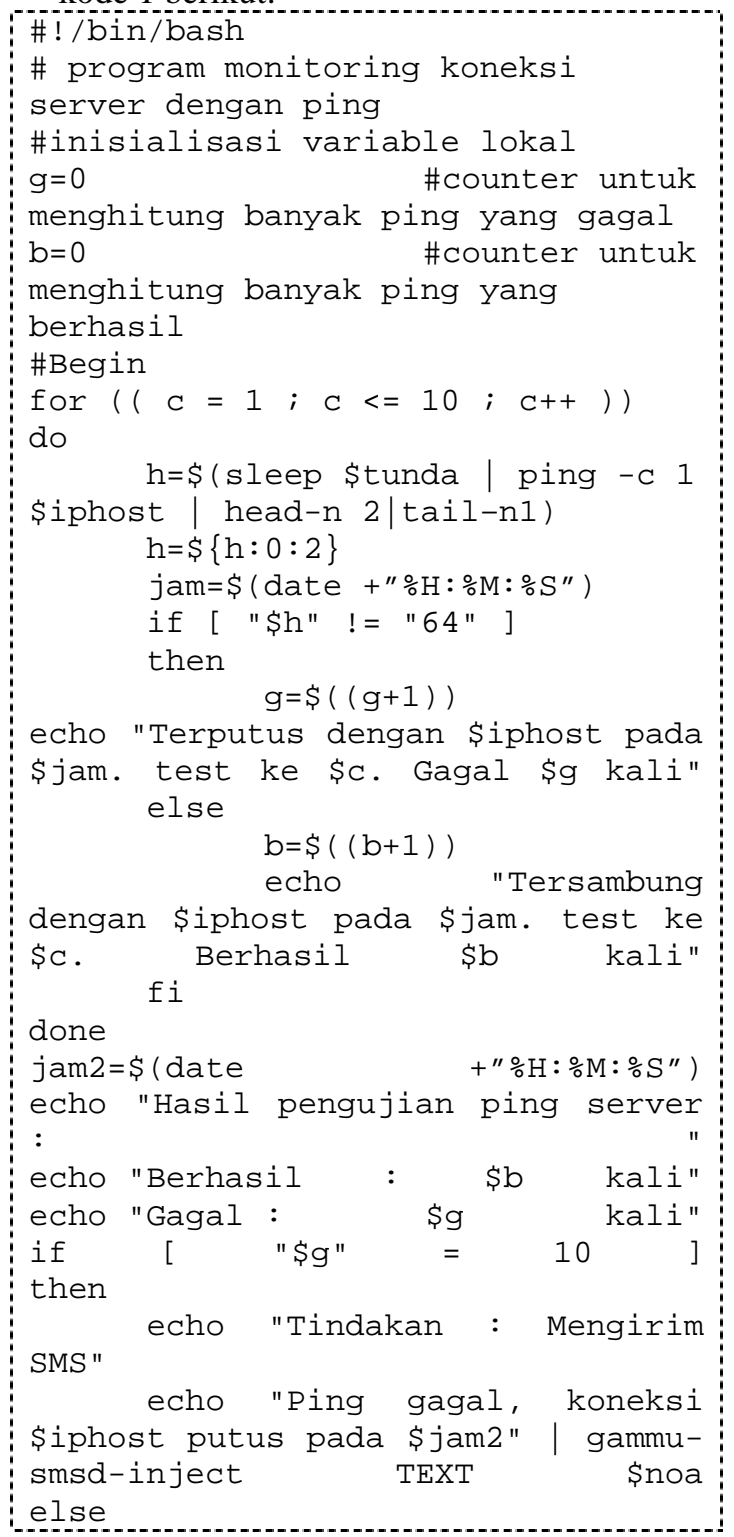




echo "Tindakan
mengirim
fi
\#End

Kode 1. Script uji koneksi dengan ping

Agar script ptest.sh dapat dijalankan, script ptest.sh harus dibuat menjadi mode executable [7].

c. Menyiapkan script uji koneksi database dengan Netcat

Pada tahap ini dibuat script yang berisi perintah untuk melakukan uji koneksi terhadap server database dan mengirim SMS sesuai dengan algoritma yang telah dibuat, implementasinya sebagaimana terlihat pada kode 2 berikut:

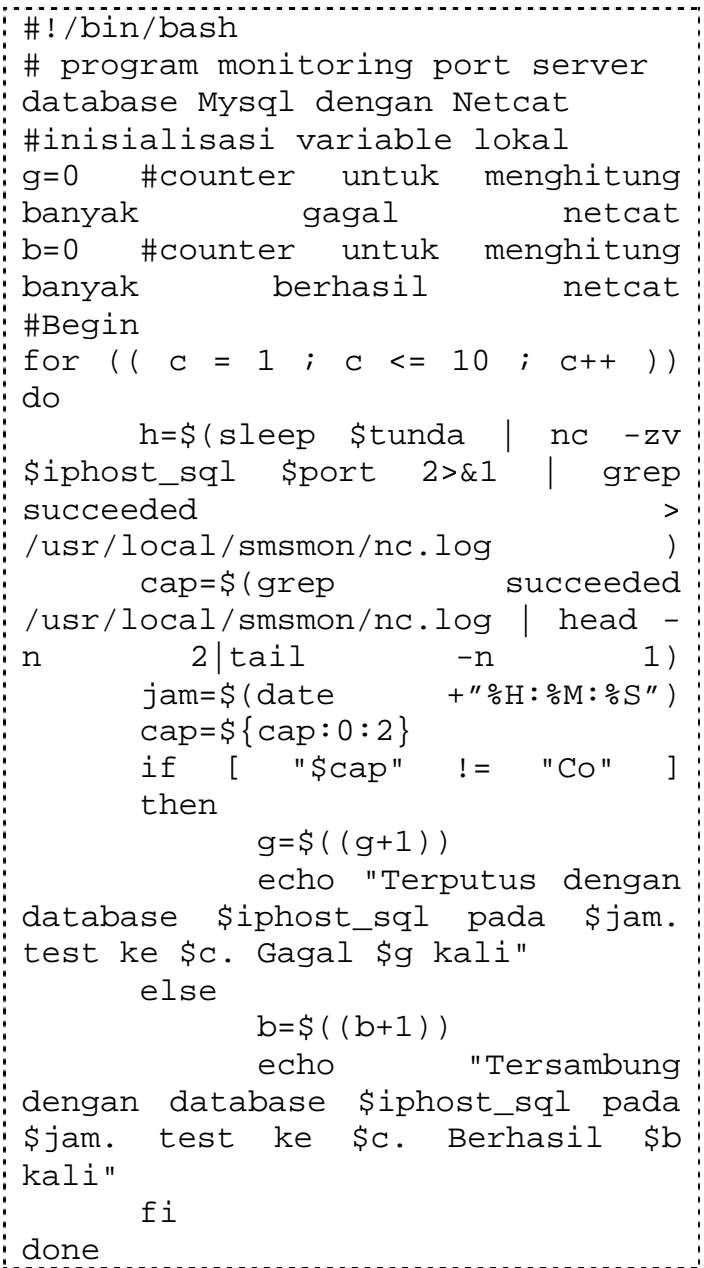

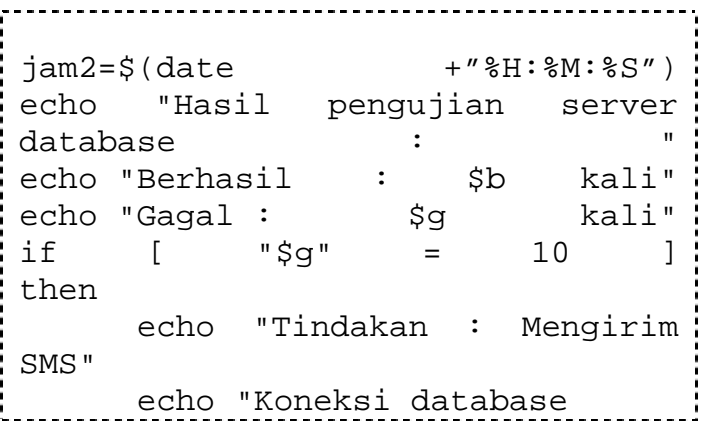

Kode 2. Script uji koneksi database

Script harus diubah ke dalam mode executable agar dapat dijalankan.

d. Membuat file konfigurasi utama sistem monitoring

Konfigurasi yang diperlukan sebagai informasi host yang akan diuji, seperti waktu tunda, nomer telpon admin, IP Address dan port menggunakan varibel global agar variabel dapat digunakan script lain [3]. Isi dari script konfigurasi ditunjukkan pada kode 3

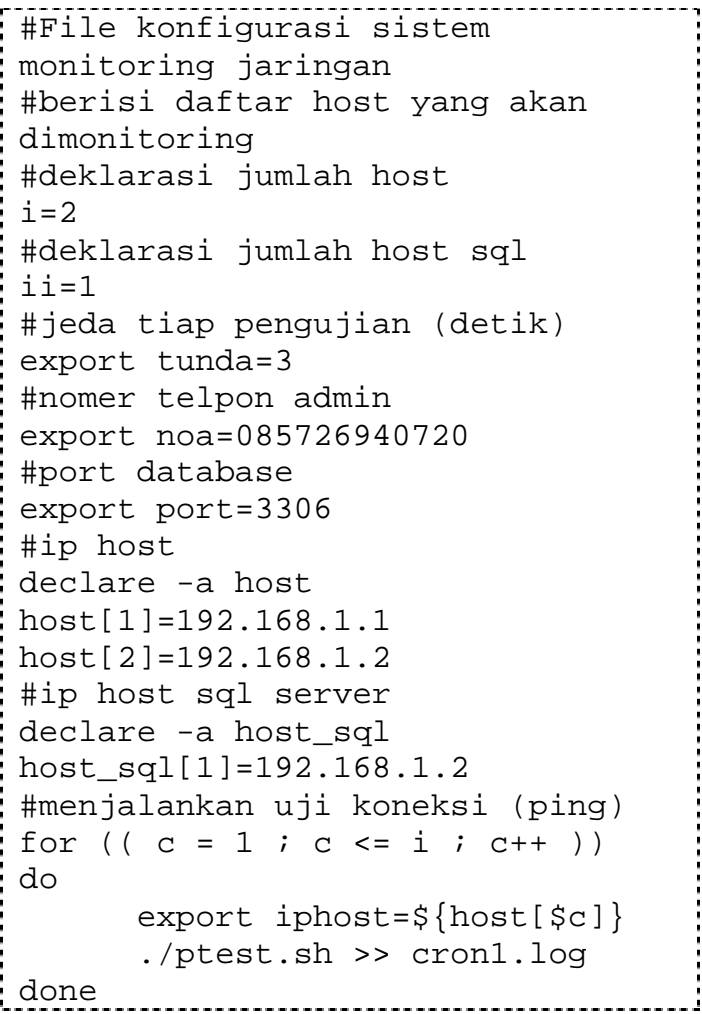




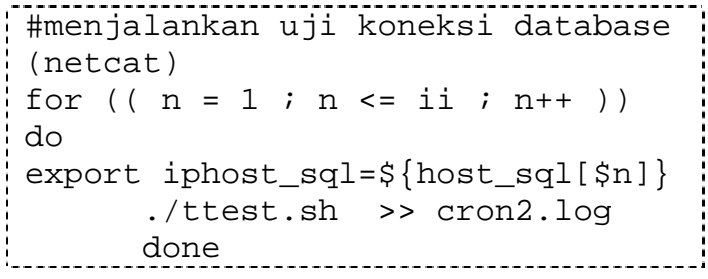

Kode 3. Script konfigurasi

e. Mengatur penjadwalan script untuk dijalankan

Sistem monitoring jaringan menggunakan SMS gateway akan melakukan pengujian koneksi selama 10 menit sekali. Untuk mengimplementasikannya,

script konfigurasi diatur penjadwalan eksekusinya menggunakan crontab. Caranya dengan mengetikkan perintah

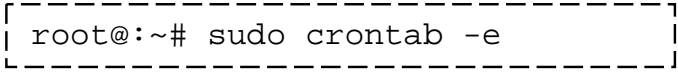

Kemudian akan terbuka editor konfigrasi crontab, selanjutnya tambahkan perintah untuk melakukan penjadwalan script konfigurasi

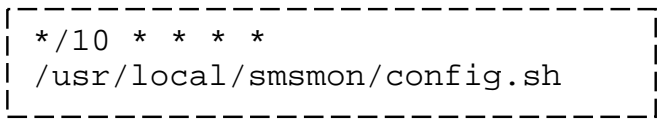

\subsection{Pengujian}

Fungsi utama sistem monitoring jaringan berbasis SMS gateway adalah memberi alert atau peringatan kepada admin mengenai konektifitas server dengan DNS dan konektifitas database server secara teraktual melalui SMS [2].

Untuk melakukan pengujian, dibuat jaringan sederhana dengan topologi seperti ditunjukkan gambar 5, kemudian dilakukan percobaan dengan melakukan monitoring

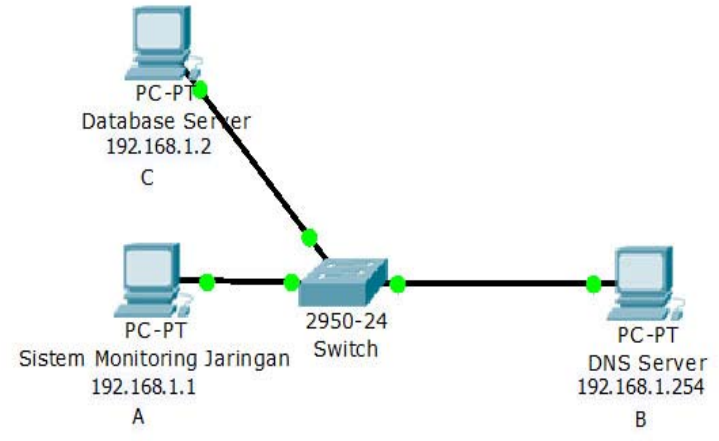

\section{Gambar 5.Topologi uji sistem monitoring jaringan dengan SMS gateway}

Berdasarkan dua fitur utama dalam sistem ini, uji koneksi menggunakan ping akan dilakukan PC A kepada DNS server PC B. Jika PC A dan PC B terhubung, hasil yang diperoleh dari monitoring ini dapat dilihat pada /usr/local/smsmon/cron1.log sebagaimana terlihat pada gambar 6 berikut.

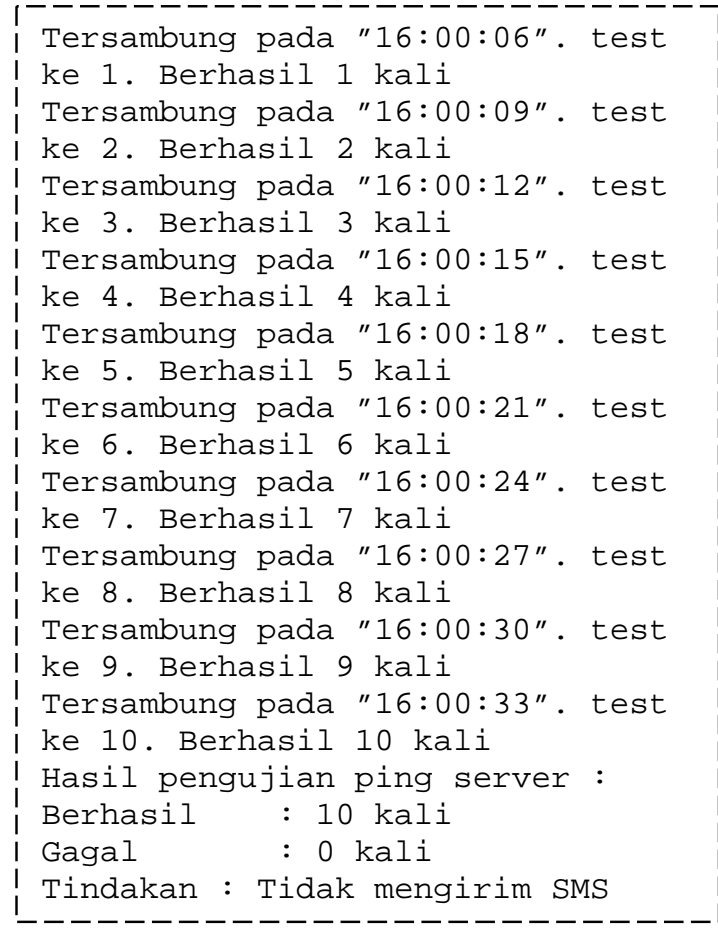

Gambar 6. Hasil monitoring konektifitas server dengan DNS dengan kondisi terhubung

Namun apabila PC A tidak dapat terhubung dengan PC B, hasil yang diperoleh dari monitoring ini dapat dilihat pada gambar 7 . 


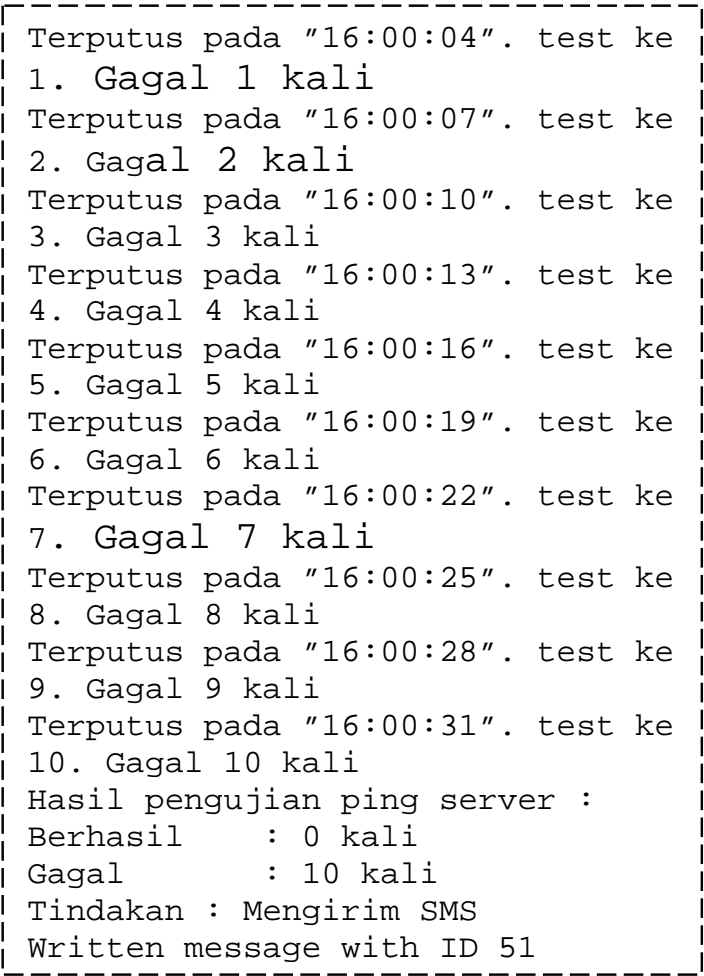

Gambar 7. Hasil monitoring konektifitas server dengan DNS dengan kondisi tidak terhubung

Ketika melakukan monitoring, apabila dalam 10 kali percobaan akses gagal, maka sistem akan megirimkan SMS kepada admin seperti gambar 8.

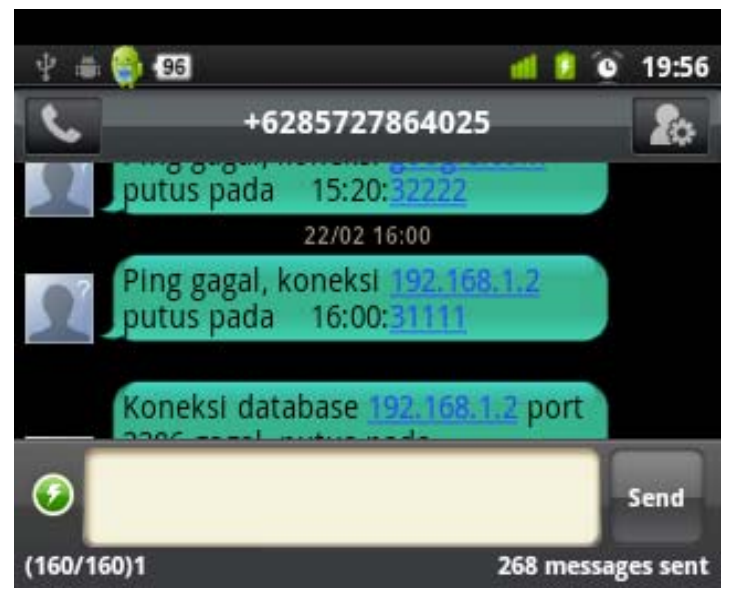

Gambar 8. Pesan diterima admin

Fitur kedua adalah pengujian koneksi database server. Dalam topologi pengujian sederhana, PC A akan melakukan pengujian koneksi database terhadap PC C dengan cara memonitor port 3306 pada PC C menggunakan aplikasi Netcat. Bila PC A terhubung dengan port database PC $\mathrm{C}$ hasil monitoring yang diperoleh dapat dilihat pada gambar 9 .

Tersambung dengan database pada | "16:00:04". test ke 1. Berhasil 1 kali

Tersambung dengan database pada |"16:00:07". test ke 2. Berhasil 2 $\mathrm{kali}$

Tersambung dengan database pada "16:00:10". test ke 3. Berhasil 3 kali

Tersambung dengan database pada "16:00:13". test ke 4. Berhasil 4 i kali

Tersambung dengan database pada "16:00:16". test ke 5. Berhasil 5 kali

Tersambung dengan database pada "16:00:19". test ke 6. Berhasil 6 kali

Tersambung dengan database pada "16:00:22". test ke 7. Berhasil 7 kali

Tersambung dengan database pada "16:0๑:25". test ke 8. Berhasil 8 kali

Tersambung dengan database pada | "16:00:28". test ke 9. Berhasil 9 kali

Tersambung dengan database pada | "16:00:31". test ke 10. Berhasil $10 \mathrm{kali}$

Hasil pengujian server database:

Berhasil : $10 \mathrm{kali}$

Gagal : 0 kali

Tindakan : Tidak mengirim SMS

Gambar 9. Hasil monitoring konektifitas database kondisi terhubung

Namun apabila PC A tidak dapat terhubung dengan port database PC C, yaitu bila dalam 10 kali akses gagal, sistem akan mengirimkan SMS kepada admin seperti gambar 10. 


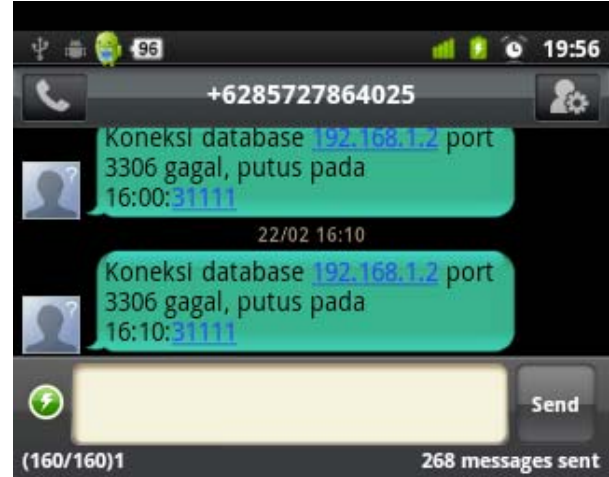

Gambar 10. Pesan diterima admin

Hasil monitoring akses database yang diperoleh dari percobaan ini dapat dilihat pada gambar 11 .

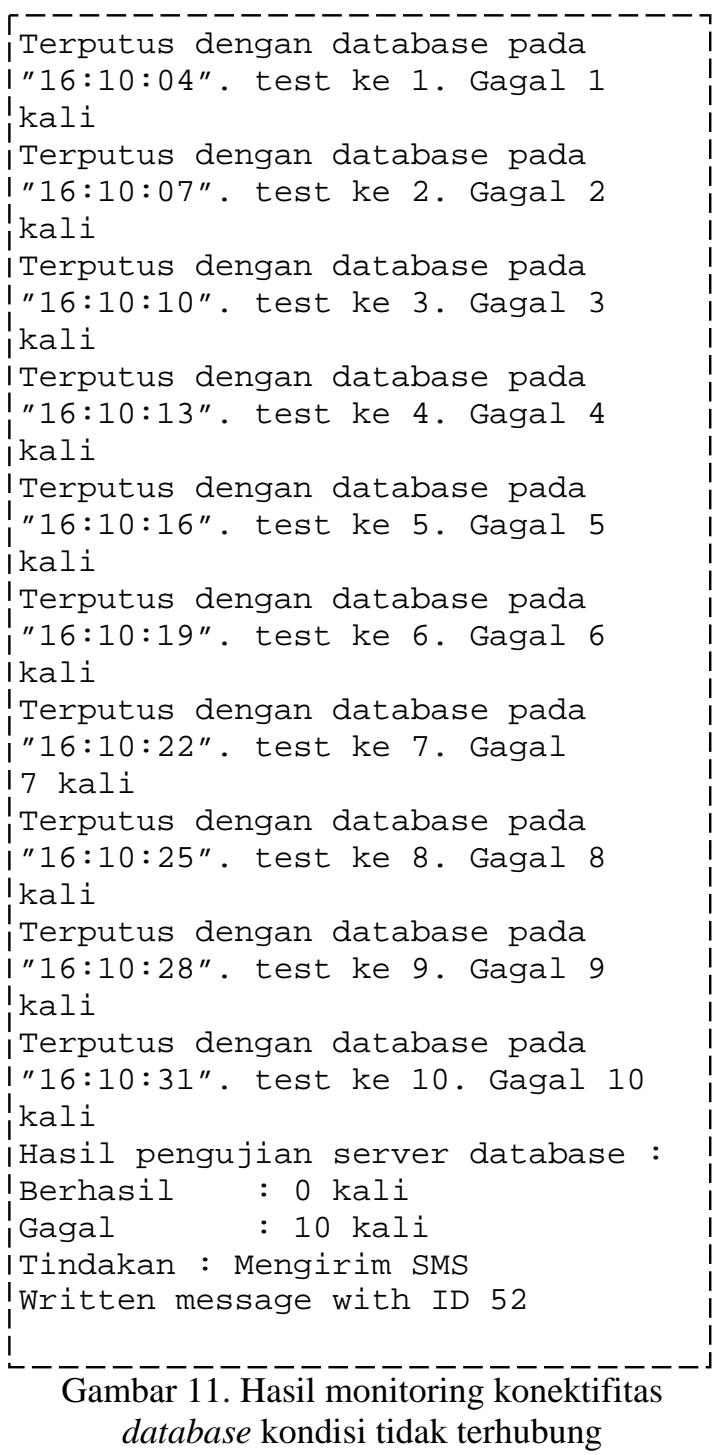

Di dalam aplikasi gammu sudah terdapat database yang menyimpan semua pesan yang dikirim maupun diterima secara otomatis. Sehingga dapat dimanfaatkan menjadi SMS log untuk implementasi sistem monitoring jaringan menggunakan SMS gateway. Seperti yang terlihat pada gambar 12 .

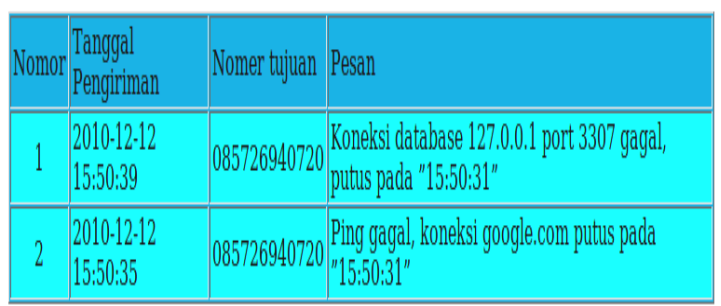

Gambar 12. SMS log yang terkirim dalam database

\section{Simpulan}

Setelah dilakukan serangkaian percobaan maka didapatkan hasil sebagai berikut:

a. Sistem monitoring jaringan dibangun untuk dapat membantu administrator jaringan mengawasi kondisi koneksi server linux.

b. Dengan memperhatikan banyaknya SMS yang terkirim pada SMS log di database, administrator dapat mengambil tindakan untuk melakukan sesuatu terhadap jaringannya.

\section{Daftar Pustaka}

[1] Eric Cole, Ronald Krutz, \& James W. Conley, 2005, "Network Security Bible", Wiley Publishing, Inc. Indianapolis, United States.

[2] Ghazali, M. 2008, “Topologi jaringan”, diakses dari

http://www.scribd.com/doc/46315374/Topo logi-Jaringan pada 12 november 2010 pukul 22.00 WIB.

[3] Lydia P, David T, Britt C. T. 2006, "TCP/IP Tutorial and Technical Overview”, IBM International Technical Support Organization, New York, United States.

[4] Machtelt Garrels, 2008, "Introduction to Linux", diakses dari http://tldp.org/LDP/intro-linux/introlinux.pdf, pada tanggal 10 januari 2011 pukul 11.00 WIB. 
[5] Tito, 2004, “Jaringan Komputer" diakses dari http://blog.unikom.ac.id/v/L5/ pada 21 Oktober 2010 pukul 18.50 WIB.

[6] Tri Wicaksono, Mohamad. 2006, "Pemrograman SMS Interaktif Berbasis Java”, Elex Media Komputindo, Jakarta.
[7] Vivek G. Gite. 1999-2002, “Linux Shell basics”, diakses dari

http://www.freeos.com/guides/lsst/ pada tanggal 23 Oktober 2010 pukul 18.50 WIB. 